\title{
OBSERVATIONS FAITES SUR UN BARRAGE EN ENROCHEMENTS
}

\author{
M. MONTAGNE
}

Chef des Services Production de l'Union Pyrénéenne

Les observations qui suivent ont été faites sur un barrage en enrochements en vrac avec masque en béton armé sur sa face amont et enrochements rangés sur sa face aval. La pente générale des deux parements est le $1 / 1$.

L'ouvrage étant situé à $2.000 \mathrm{~m}$. d'altitude, on a voulu, par le choix du type de construction, réduire les sommes importantes à consacrer aux transports du poids considérable de ciment exigé par un barrage poids en béton. En fait, la construction, étudiée et exécutée sous la direction de M. Vennin, Ingénieur en chef des Pour dres, a été très économique. Ses dimensions sont :

- longueur en crête : $240 \mathrm{~m}$.

- hauteur au-dessus des fondations : $25 \mathrm{~m}$.

— volume des matériaux : $53.000 \mathrm{~m}^{3}$ environ.

Le masque en béton, du type mince, c'est-à-dire de l'épaisseur de l'ordre de $1 / 60$, de la hauteur du barrage et à raccordement parabolique avec le parafouille, a par-" faitement suivi, sans fissures notables, les mouvements de tassement qui ont suivi les deux premières mises en eau. Seul, un léger décollement s'est produit en $d$ (coupe ci-jointe). Ce décollement, très localisé, n'a pas donné lieu à des fuites et ne s'est pas, après réparation, reproduit lors du deuxième remplissage.

Au cours de la construction, il a été décidé d'augmenter de $2 \mathrm{~m}$. 50 la cote du plan d'eau maximum. A ce moment-là, la mise en place des enrochements rangés de la face aval ne permettant pas de reprendre l'ouvrage au pied, il a été décidé de le surélever, dans la partie la plus haute, à l'aide d'éléments en maçonnerie indépendants les uns des autres, afin d'éviter les lézardes qui se seraient fatalement produites au cours des tassements des enrochements. Comme on le voit sur la coupe ci-jointe, le masque en béton armé s'appuie aussi, dans sa partie haute, sur les éléments en maçonnerie.

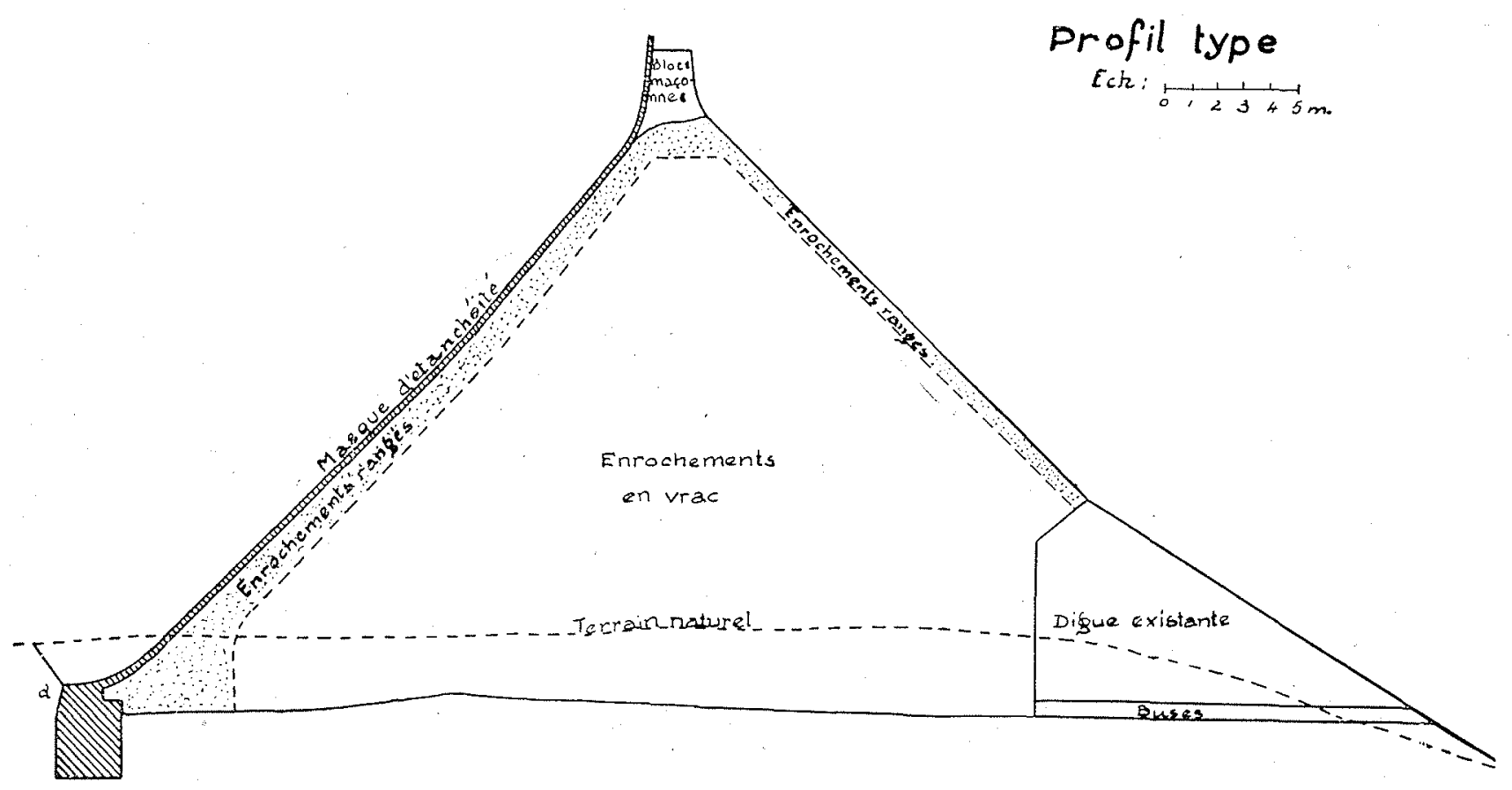


Avant la première mise en eau, des repères avaient été scellés, sur le couronnement en particulier, afin de permettre la mesure des déplacements du couronnement. Les déplacements horizontaux prévus devaient être de l'ordre de $0 \mathrm{~m} .25$. Or, ces déplacements, causés surtout par les ruptures de tous les éléments placés en porte à faux (la carrière voisine ouverte dans les schistes gris ordoviciens a fourni des éléments plats constituant, en somme, des dalles), atteignaient déjà $0 \mathrm{~m} .23$, alors que le plan d'eau devait encore être élevé de $2 \mathrm{~m}$. A cette cote, le remplissage a été arrêté jusqu'au moment où des mesures dans le plan vertical ont montré que la défor-* mation de l'ouvrage se poursuivait suivant un angle voisin de $45^{\circ}$ sur l'horizontale et que, par suite, il pouvait être continué sans danger. La déformation totale du couronnement a atteint $0 \mathrm{~m} .30$ dans un plan vertical, au centre de l'ouvrage.

Les observations les plus intéressantes ont porté sur les plissements des enrochements rangés qui se sont surtout produits sur le parement aval, immédiatement audessus du contact avec une partie plus ancienne de l'ouvrage déjà tassée et destinée, en somme, comme dans les parties similaires des barrages en terre, à servir de butée. Ces plissements ont été, dès le début, jugés sans gravité. Le tassement en $\%$ d'enrochements en vrac étant déjà supérieur à celui d'enrochements rangés, on doit, en effet, tenir compte que la plus grande poussée de l'eau se reporte d'autant plus sur le parement aval que le rapport de la longueur de ce dernier aux dimensions transversales de l'enrochement en vrac est plus petit. Or, la coupe ci-jointe montre que ce rapport est sensiblement inférieur à un. Les enrochements rangés se sont donc plissés jusqu'à ce que les enrochements en vrac supportent l'effet principal. En fait, les plissements ont atteint des flèches de $0 \mathrm{~m}$. 50 à $0 \mathrm{~m}$. 60 sans dommage pour l'ensemble de l'ouvrage et ils ont même pu être repris en sous- $x$ cuvre sans aucune difficulté et sans abaissement du plan d'eau.

Quant aux mouvements des éléments en maçonnerie du couronnement, ils ont été minimes. Si le garde-corps en béton armé qui surmonte ces éléments du côté de l'eau, avait été construit après le deuxième remplissage, ils ne seraient pas apparents. 